\title{
Short-term effects of treadmill exercise on metabolic, physiological and hemodynamic functions of apparently healthy individuals
}

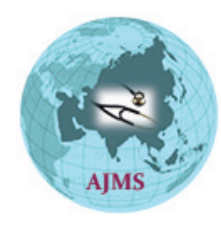

\author{
Ojiako Nkiruka Peace ${ }^{1}$, Onyeanusi Joel ${ }^{2}$, Onyekwelu Kenechukwu Chibuike ${ }^{3}$, \\ Ufelle Silas Anayochukwu ${ }^{4}$, Okoli Uzoamaka Adaobi ${ }^{5}$, Nwokike Matthew ${ }^{6}$ \\ ${ }^{1}$ Medical Laboratory Scientist, ${ }^{2,4}$ Lecturer, Departments of Medical Laboratory Science, ${ }^{3}$ Lecturer, ${ }^{5}$ Lecturer, Department \\ of Medical Biochemistry, College of Medicine, University of Nigeria, Enugu Campus, Enugu, ${ }^{6}$ Lecturer, Department of \\ Pharmacology and Therapeutics, Ebonyi State University Abakaliki, Nigeria
}

Background: According to the World Health Organization (WHO), 60 to $85 \%$ of the population worldwide does not engage in enough activity; making physical inactivity the fourth leading risk factor for global mortality. Aims and Objectives: This study evaluated the effect of treadmill exercise on liver enzymes, lipid profile, glucose, albumin, blood pressure and pulse rate of apparently healthy students of Nigerian Law School, Enugu Campus, Enugu State Nigeria. Materials and Methods: Sixty (60) students (30 males and 30 females) within the age bracket of 21-35 years were recruited for this study. The anthropometric parameters: height $(\mathrm{m})$ and weight $(\mathrm{kg})$ were taken and used in the calculation of body mass index (BMI). Blood samples were collected from the subjects for the determination of liver enzymes, lipid profile, glucose and albumin levels before and immediately after exercise. Anthropometric parameters, blood pressure and pulse rate were also measured before and immediately after exercise. The blood samples collected were analyzed in the laboratory for albumin, glucose, lipid profile (triglyceride, total cholesterol, high density lipoprotein (HDL) and low density lipoprotein (LDL)), liver enzyme (aspartate transaminase (AST), alanine transaminase (ALT) and alkaline phosphate (ALP)) using standard methods as described in materials and methods. Results: There were significant difference $(p<0.05)$ between the mean pulse rate and blood pressure before and after treadmill exercise. There were also significant difference $(p<0.05)$ between the mean glucose, AST, ALT, ALP, total cholesterol and albumin before and after exercise. Conclusion: Findings from this study revealed that tread mill exercise has a short term effect of the metabolic, physiological and hemodynamic functions of the exercising individuals.

Access this article online

Website:

http://nepjol.info/index.php/AJMS

DOI: 10.3126/ajms.v9i1.17347

E-ISSN: 2091-0576

P-ISSN: 2467-9100

Key words: Exercise, Blood pressure, AST, ALT, ALP, BMI, HDL, LDL

\section{INTRODUCTION}

The role of exercise in the physical health and wellbeing of an individual has long been established. Exercise is an integral component of the daily activity of most physically active individuals which is associated with both long-term and short-term metabolic, physiological and hemodynamic changes which can impart either positively or negatively on the health of the exercising subjects. ${ }^{1}$
Exercise has been demonstrated to be associated with a range of health benefits while absence of exercise is associated with coronary heart disease, certain forms of cancer, obesity, hypertension and diabetes. ${ }^{2}$ Results from epidemiological studies showed that regular exercise and physical activity reduces risk of cancer and mortality. ${ }^{3,4} \mathrm{An}$ acute bout of exercise places a wide spectrum of demands on the body, depending on the form, intensity and duration of the exercise. High-intensity exercise causes tissue 
damage, production of stress hormones, and alterations in the circulating quantity and function of various immune cells. Exercise is known to have positive effects on structural adaptions of the CNS, ${ }^{5}$ have a preventive effect in developing neurodegenerative disorders like Alzheimer and Parkinson ${ }^{6}$ and leads to an increased expression of neurotrophic and neuroprotective factors such as the brain-derived neurotrophic factor, ${ }^{7}$ the vascular endothelial growth factor ${ }^{8}$ and the insulin like growth factor. ${ }^{9}$ Engagement in physical activity is recognized as a contributor to a range of positive outcomes in physical and mental health, social well-being and cognitive and academic performances. Regular physical activity is also linked with important health outcomes such as reduction in cardiovascular disease, type 2 diabetes, depression, weight management, cognitive function and quality of life. Studies have shown that those who are physically active and participate in exercise are less likely to engage in unhealthy behavior such as substance abuse and risky sexual activities than those not involved. Engagement in exercise program improves self esteem and alleviates negative symptoms associated with schizophrenia such as depression, low self esteem and social withdrawal.

This study was conducted to determine the short-term effects of treadmill exercise on metabolic, physiological and hemodynamic functions of apparently healthy individuals. Observations from this study in combination with the findings from other studies will serve as a guide in the use of exercise to improve the health of both apparently healthy as well as sick individuals.

\section{MATERIALS AND METHODS}

\section{Subjects}

Sixty students (30 males and 30 females) within the age bracket of 20 to 35 years who were apparently healthy and with no medical condition that could affect exercise performance participated in this study. The subjects were recruited from Nigerian Law School, Enugu Campus after obtaining their informed consent. The participants were selected based on their ability to perform a maximum effort exercise, within the age bracket of 20-35 years and have a resting blood pressure of between $90 / 60 \mathrm{mmHg}$ to $130 / 85 \mathrm{mmHg}$. Subjects with cardiovascular, peripheral vascular or respiratory diseases and orthopedic or musculoskeletal lesions were excluded from this study.

\section{Collection of blood samples}

Blood samples were collected from the subjects before and immediately after treadmill exercise and before any breakfast. About $10 \mathrm{ml}$ of blood was drawn from each subject from the anti-cubital vein before and immediately after exercise into plain test tube. The clotted samples were centrifuged to extract the serum and was stored at $-20^{\circ} \mathrm{C}$.

\section{Anthropometric indices}

The height $(\mathrm{m})$ and body weight $(\mathrm{kg})$ of the subjects were measured before and after exercise and used in the calculation of body mass index (BMI). The systolic and diastolic blood pressure $(\mathrm{mmHg})$ and pulse rate were also measured.

\section{Biochemical assays}

The measurement of serum albumin was done by the direct spectrophotometric method as described by Rodkey (1965).$^{10}$ The colorimetric method as described by Somogyi $(1945)^{11}$ was used in the determination of blood glucose. Serum cholesterol was determined by enzymatic (CHODPAP) colorimetric method as described by McGowan et al., (1983)..$^{12}$ The enzymatic method as described by Tietz $(1990)^{13}$ was adopted in the estimation of triglycerides. The estimation of HDL cholesterol was performed using the method described by Burstein et al., $(1980)^{14}$ while the method of Assman et al., (1984) ${ }^{15}$ was adopted in the determination of LDL cholesterol. Aspartate transaminase (AST) and alanine transaminase (ALT) were determined by Reitman and Frankel method of $1957^{16}$ while serum alkaline phosphate (ALP) was determined by King and Armstrong method of $1934 .{ }^{17}$

\section{Ethics}

The procedures followed in this study were in accordance with the ethical standards of ethics committee on human experimentation.

\section{Data analysis}

All data collected were subjected to statistical analysis using the statistical package for the social science (SPSS) version 17.0, Chicago, IL, USA. Chi-square was used to test the significance of proportions, with $\mathrm{p}<0.05$ taken as significant.

\section{RESULT}

Of the subjects that participated in this study, $30(50 \%)$ were males and $30(50 \%)$ were females, giving a total study population of 60 participants. Of the male population, $9(30 \%)$ were in the age interval of $20-25$ years, $18(60 \%)$ were in the age range of 26-30 years, while only $3(10 \%)$ were in the age bracket of 31-35. In contrast, 19 (63.3\%) of females were in the age interval of 20- 25 years, 11 (36.7\%) were found in the age bracket of 26-30 years, while none (0) was seen in the age range of 31-35 years. Finally, of the total study population of 60 participants, 28 participants 
$(46.7 \%)$ were found to be in the age interval of $20-25$ years, $29(48.3 \%)$ were in the age range of $26-30$ years, while only $3(5 \%)$ were in the age interval of $31-35$ years (Figure 1$)$.

Table 1 shows the height, weight, body mass index, systolic and diastolic blood pressure, pulse rate before and after treadmill exercise. It shows that there was statistically significant difference $(\mathrm{p}<0.05)$ between the mean pulse rate and blood pressure before and after treadmill exercise. No statistically significant difference was observed between the mean height, weight, body mass index and duration pre and post treadmill exercise.

Table 2 shows the glucose, AST, ALT, ALP, cholesterol, triglycerides, HDL, LDL and albumin levels before and

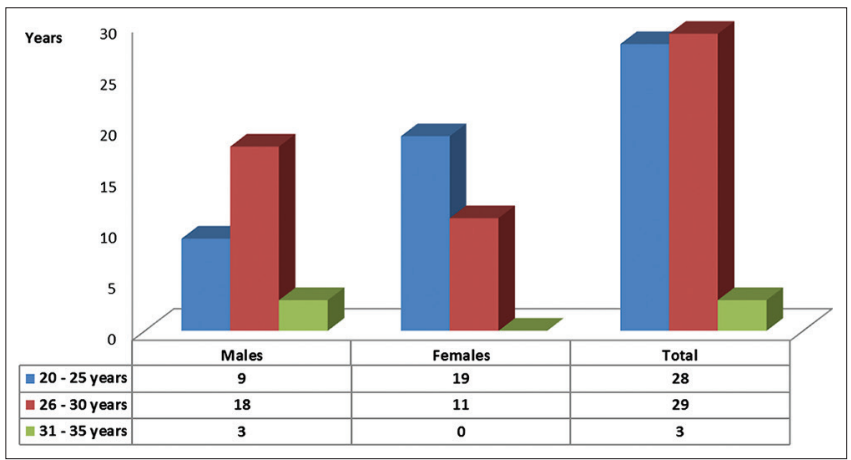

Figure 1: Age and sex related distribution of study participants after treadmill exercise. It shows that there was statistically significant difference $(p<0.05)$ between the mean glucose, AST, ALT, ALP, Cholesterol and albumin before and after treadmill exercise. However, no significant difference was observed in mean triglycerides, HDL and LDL pre and post treadmill activity.

\section{DISCUSSION}

The effect of exercise on some physical and biochemical parameters of the subjects was observed in this study. Human blood pressure comprises of systolic and diastolic blood pressure. Higher systolic blood pressure was observed in this study after the exercise (Table 1). This observation is in collaboration with the study carried out by Davis and Brown, 2001 ${ }^{18}$. Amon et al., (1984) ${ }^{19}$ in their study reported that during treadmill exercise in the normal subjects, systolic blood pressure is expected to rise to between 5 to $10 \mathrm{mmHg}$ per metabolic equivalent of effort. A decrease in the diastolic blood pressure was recorded in this study and this could be attributed to the vasodilatation of arterial blood vessels in response to the exercise bouts. ${ }^{20}$ After exercise the pulse rate of the subjects increases because the heart pumped in more oxygenated blood to the body, since more energy is needed by the muscle, the heart quickly deliver more blood to the other parts of the body to replenish oxygen

Table 1: Height, weight, body mass index, systolic and diastolic blood pressure, pulse rate pre and post treadmill exercise

\begin{tabular}{|c|c|c|c|c|}
\hline \multirow[t]{2}{*}{ Anthropometric Indices } & \multicolumn{2}{|c|}{ Mean $\pm S D$} & \multirow[t]{2}{*}{ z-score } & \multirow[t]{2}{*}{$\mathrm{p}$ value } \\
\hline & Pre $(n=60)$ & Post $(n=60)$ & & \\
\hline Height (m) & $1.66 \pm 0.07$ & $1.66 \pm 0.07$ & 0.00 & 1.00 \\
\hline Weight (kg) & $66.67 \pm 7.54$ & $66.67 \pm 7.54$ & 0.00 & 1.00 \\
\hline Body mass index $\left(\mathrm{kg} / \mathrm{m}^{2}\right)$ & $24.13 \pm 2.48$ & $24.13 \pm 2.48$ & 0.00 & 1.00 \\
\hline Systolic blood pressure $(\mathrm{Hg})$ & $124.88 \pm 5.88$ & $140.53 \pm 8.14$ & 12.07 & $<0.001^{*}$ \\
\hline Diastolic blood pressure $(\mathrm{Hg})$ & $81.36 \pm 6.52$ & $65.85 \pm 10.50$ & 9.72 & $<0.001^{*}$ \\
\hline Pulse rate & $80.23 \pm 14.93$ & $104.21 \pm 12.81$ & 9.44 & $<0.001^{*}$ \\
\hline
\end{tabular}

Table 2: Means levels of glucose, AST, ALT, ALP, total cholesterol, triglycerides, LDL, HDL, and albumin pre and post treadmill exercise

\begin{tabular}{|c|c|c|c|c|}
\hline \multirow[t]{2}{*}{ Biochemical indices } & \multicolumn{2}{|c|}{ Mean \pm SD } & \multirow[t]{2}{*}{ z-score } & \multirow[t]{2}{*}{$p$ value } \\
\hline & Pre $(n=60)$ & Post $(n=60)$ & & \\
\hline Glucose (mmol/l) & $4.65 \pm 0.45$ & $3.84 \pm 0.45$ & 9.89 & $<0.001^{*}$ \\
\hline ALT (U/I) & $6.00 \pm 2.06$ & $9.00 \pm 2.46$ & 7.25 & $<0.001^{*}$ \\
\hline ALP (iu/l) & $34.65 \pm 4.17$ & $40.13 \pm 4.00$ & 7.34 & $<0.001^{*}$ \\
\hline Total cholesterol (mmol/l) & $4.59 \pm 0.28$ & $4.31 \pm 0.31$ & 5.19 & $<0.001^{*}$ \\
\hline Triglycerides $(\mathrm{mmol} / \mathrm{l})$ & $0.84 \pm 0.12$ & $0.87 \pm 0.13$ & 1.42 & 0.158 \\
\hline $\mathrm{LDL}(\mathrm{mmol} / \mathrm{l})$ & $3.04 \pm 0.37$ & $3.07 \pm 0.34$ & 0.35 & 0.730 \\
\hline $\mathrm{HDL}(\mathrm{mmol} / \mathrm{l})$ & $1.11 \pm 0.16$ & $1.14 \pm 0.16$ & 1.13 & 0.262 \\
\hline Albumin $(g / l)$ & $32.20 \pm 2.97$ & $35.71 \pm 3.15$ & 6.28 & $<0.001^{*}$ \\
\hline
\end{tabular}


and nutrient stored, the faster the heart pump blood, the higher the pulse rate. ${ }^{21}$

The mean plasma glucose levels of the subjects after exercise were significantly lower than their mean plasma glucose levels before the exercise. The reason for this finding is not unrelated to the fact that exercise lowers blood glucose. As muscles do their work during the exercise, they obtain energy from glucose stored in the muscle as glycogen. When these supplies of glycogen run low, glucose from the blood stream is used as energy source. After the exercise, the body replaces the stores of glycogen in the muscle and the liver which lower blood glucose levels even more.

The present results show that there was an increasein liver enzymes (ALT, AST, and ALP). The higher plasma liver enzymes activity observed in the subjects after exercise can be associated with the leaking of these enzymes from mechanically damaged muscle cells into the surrounding interstitial fluids. This finding is in line with the report of a study carried out by Mena et al (1996) ${ }^{22}$, which reported a significant increase in the plasma enzyme level. The mean serum ALP activities of the subjects after the exercise were significantly higher than their mean serum ALP activities before the exercise. The higher plasma ALP activity observed in the subjects after the exercise as compared to their pre-exercise values can be as a result of haemoconcentration that occurs during the exercise due to increased sweating, increased body temperature or splenic contraction.

The lipid profile of the subjects before and after the exercise was also observed. The mean serum total cholesterol levels of the subjects after exercise was significantly lower than their mean serum levels before exercise and this shows that exercise lowers total cholesterol. The mean serum albumin levels of the subjects after exercise were significantly higher $(p<0.05)$ than their mean serum albumin levels before exercise. These findings may result from several factors that contribute to the increase in plasma albumin content such as hepatic interstitial albumin concentration, circulating levels of cortisol, catecholamine, thyroid hormone, glucagon, epinephrine, nutritional state, a redistribution of albumin from the interstitial to the intravascular space and reduced trans-capillary escape rate of albumin. ${ }^{23}$

\section{CONCLUSION}

Findings from this study revealed that physical exercise had short-term effects on the metabolic, physiologic and hemodynamic functions of the exercising individuals.
These short-term effects are beneficial health-wise and have the potential to optimally improve the health of both apparently healthy and sick individuals.

\section{REFERENCES}

1. Wislett $U$, Ellingsen $\mathrm{O}$ and Kemi $\mathrm{O}$. High intensity interval training to maximize cardiac benefit of exercise training. Exercise and Sports Sciences Reviews 2009;37 (3) 139-146.

2. Centre for Disease Control. Physical activity and health: a report of the surgeon general. U.S. Department of Health and Human Services, National Center for Chronic Disease Prevention and Health Promotion, Atlanta 1996.

3. Zhong S, Ma T, Chen L, Chen W, Lv M, Zhang X and Zhao J. Physical Activity and Risk of Lung Cancer: A Meta-analysis. Clin J Sport Med 2016;26(3):173-181.

4. Schmid D and Leitzmann MF. Association between physicalactivity and mortality among breast cancer and colorectal cancersurvivors: a systematic review and meta-analysis. Annals of Oncology 2014; 25(7):1293-1311.

5. Erickson KI, Leckie RL and Weinstein AM. Physical activity, fitness, and gray matter volume Neurobiology of Aging 2014; 35 : S20-S28.

6. Mattson MP. Lifelong brain health is a lifelong challenge: from evolutionary principles to empirical evidence. Aging Research Reviews 2015;20:37-45.

7. Szuhany KL, Bugatti M, and Otto MW. A meta-analytic review of the effects of exercise on brain-derived neurotrophic factor. Journal of Psychiatric Research 2015; 60:56-64.

8. De Almodovar CR, Lambrechts D, Mazzone M, and Carmeliet P. Role and therapeutic potential of VEGF in the nervous system. Physiological Reviews 2009;89(2):607-648.

9. Skriver K, Roig M, Lundbye-Jensen J, Pingel J, Helge JW, Kiens B and Nielsen JB. Acute exercise improves motor memory: exploring potential biomarkers. Neurobiol Learn Mem 2014; 116:46-58.

10. Rodkey F. Direct Spectrophotometric Determination of albumin in human serum. Clin Chem 1965; 11: 478-487.

11. Somogyi M. The colorimetric determination of blood glucose. J Biol Chem1945; 160: 61.

12. McGowan MW, Artiss JD, Strandbergh DR and Zak BA. Peroxidase-coupled method for the colorimetric determination of serum triglycerides. Clinical Chemistry 1983;29: 538.

13. Tietz NW. Clinical guide to Laboratory Tests ( $2^{\text {nd }}$ ed) 1990 . W.B. Saunders Company: Philadelphia, USA; 554-556.

14. Burstein M, Scholnick HR and Morfin R. Rapid method for the isolation of lipoproteins from serum by precipitation with poly anions. Scandinavian Journal of Clinical and Laboratory Investigation 1980;40: 583-595.

15. Assman G, Jabs HU, Kohnert U, Nolte W and Schriewer H. LDL cholesterol determination in blood serum following precipitation of LDL with polyvinyl sulphate. Journal of Analytica Chimica Acta 1984;140:77-83.

16. Reitman $S$ and Frankel SA colorimetric method for the determination of serum glutamic oxalacetic and glutamic pyruvic transaminases. Am J Clin Pathol 1957; 28 (1) 56-63.

17. King EJ and Armstrong ARA. Convenient method for determining serum and bile phosphatase activity. Can Med Assoc J 1934; 31(4) 376-381.

18. Davis JM and Brown AS. Carbohydrates, hormones and endurance performance. Sports Science Exchange 2001; 14: 1-4.

19. Amon $\mathrm{KW}$, Richards $\mathrm{KL}$ and Crawford $\mathrm{MH}$. Usefulness of post 
exercise response of systolic blood in the diagnosis of coronary disease. American Heart Journal 1984; 70: 951-956.

20. Kelly 2000. Diastolic Blood Pressure during Exercise. www. ehow.com/about.5074637.

21. Diane $U$. Why heart rate increases during exercise-how cardiovascular exercise causes the pulse rate to rise. Moronacity Health Journal 2010. Moronacity.com. Accessed on 7 Jan 2017.
22. Mena P, Maynar M and Campillo JE. Changes in plasma enzyme activities in professional racing cyclists. Br J Sports Med 1996; 30: $122-124$

23. Gillen CM, Lee R, Mack EW, Tomaselli CM, Nishiyasu T and Nadel ER. Plasma volume expansion in human after a single intense exercise protocol. Journal of Applied Physiology 1991;71:1914-1920.

Authors Contribution:

ONP, OJ- Conception, design, data collection, laboratory analysis, literature search and critical revision of the manuscript; OKC, USA, OUA, NM-Data collection, literature search/review, statistical analysis/interpretation, preparation of the manuscript and critical revision of the manuscript.

Orcid ID:

Dr. Kenechukwu Onyekwelu: (1) http://orcid.org/0000-0001-8515-9456

Source of Support: Nil, Conflict of Interest: None declared. 